\title{
Interaction of hydroxyapatite nanoparticles with endothelial cells: internalization and inhibition of angiogenesis in vitro through the PI3K/Akt pathway
}

This article was published in the following Dove Press journal:

International Journal of Nanomedicine

10 August 2017

Number of times this article has been viewed

Xingxing Shi*

Kai Zhou*

Fei Huang

Chen Wang

Department of Prosthodontics, Jiangsu Key Laboratory of Oral Diseases, Affiliated Hospital of Stomatology, Nanjing Medical University, Nanjing, People's

Republic of China

*These authors contributed equally to this work
Correspondence: Chen Wang Department of Prosthodontics, Jiangsu Key Laboratory of Oral Diseases, Affiliated Hospital of Stomatology, Nanjing Medical University, No 136, Han-zhong Road, Nanjing 210029,

People's Republic of China

Tel +86258503 I83।

Email chwang9122@sina.com
Abstract: Nano-hydroxyapatite (nano-HAP) has been proposed as a better candidate for bone tissue engineering; however, the interactions of nano-HAP with endothelial cells are currently unclear. In this study, HAP nanoparticles (HANPs; $20 \mathrm{~nm}$ np20 and $80 \mathrm{~nm} \mathrm{np80)}$ and microsized HAP particles (m-HAP; $12 \mu \mathrm{m}$ ) were employed to explore and characterize cellular internalization, subcellular distribution, effects of HANPs on endothelial cell function and underlying mechanisms using human umbilical vein endothelial cells (HUVECs) as an in vitro model. It was found that HANPs were able to accumulate in the cytoplasm, and both adhesion and uptake of the HANPs followed a function of time; compared to np80, more np20 had been uptaken at the end of the observation period. HANPs were mainly uptaken via clathrin- and caveolin-mediated endocytosis, while macropinocytosis was the main pathway for m-HAP uptake. Unexpectedly, exposure to HANPs suppressed the angiogenic ability of HUVECs in terms of cell viability, cell cycle, apoptosis response, migration and capillary-like tube formation. Strikingly, HANPs reduced the synthesis of nitric oxide (NO) in HUVECs, which was associated with the inhibition of phosphatidylinositol 3-kinase (PI3K) and phosphorylation of eNOS. These findings provide additional insights into specific biological responses as HANPs interface with endothelial cells.

Keywords: HANPs, HUVECs, internalization, angiogenesis, PI3K/Akt

\section{Introduction}

As a representative of the bioactive ceramic, hydroxyapatite (HAP) exhibits excellent osteoconductivity and biocompatibility, rendering it a good candidate for bone tissue engineering and components of dental implants. ${ }^{1-3}$ However, insufficient mechanical strength and slow biodegradability of HAP restrict extensive application, and the limitations of HAP reignite intense interest in the development of nano-HAP, to some degree mimicking the inorganic component of native bone matrix. Recently, nano-HAP has been reported as a better candidate for bone repairs and implants such as scaffolds, filling materials and bioactive coatings on materials such as titanium and its alloys. ${ }^{4-6}$ Investigations have revealed that nano-HAP powders possess improved densification and sinterability due to increased surface area, which could ameliorate fracture toughness, and other mechanical properties. ${ }^{7}$ In addition, nano-HAP, compared to HAP, showed favorable effect on cell proliferation of human osteoblast-like cells in vitro and stimulated hard tissue regeneration in vivo. ${ }^{8,9}$ Nevertheless, the exact role of nano-HAP in bone repair, especially the actual relationship between nano-HAP and important cells involved in bone regeneration, is far from being clarified, and the biocompatibility of nano-HAP is still a matter of debate. 
Once HAP nanoparticles (HANPs) have entered the body as artificial bone materials, endothelial cells (ECs) lining the lumen of blood vessels will inevitably come into contact with them. ECs not only are implicated in angiogenesis but also serve as biological barrier, mediating removal of nanoparticles (NPs) to maintain body homeostasis. ${ }^{10,11}$ Therefore, interactions of HANPs with ECs are one of the most important items to understand the bioactivity and biocompatibility of nano-HAP. A general consensus exists that a detailed understanding of the process and mechanisms underlying cellular NPs uptake is crucial for exploring the effects of nanomaterials on biological systems and evaluating their potential harm to organisms, which will promote a safer and more efficient application of nanomaterials in biomedical fields. So far, a study by Bauer et a ${ }^{12}$ revealed that HANPs as drug and gene delivery system could be internalized by liver cancer cells through clathrin-mediated endocytosis. Santos et $\mathrm{al}^{13}$ found that HANPs were readily uptaken by osteoblastic cells via endocytosis. However, to our knowledge, there are few reports on the internalization of HANPs in ECs and the precise mechanisms that might mediate such process.

Bone repair highly relies on angiogenesis to provide metabolic needs, such as nutrients, renewable autologous cells and various growth factors. Since ECs account for vascular formation, an ideal bone substitute should have stimulatory ability for EC functions. Therefore, it is central to understand the influence of HANPs on ECs actions, such as cellular proliferation and migration. It has been reported that ECs maintain biochemical and morphological markers of healthy endothelium in the presence of HAP nanocrystals. ${ }^{14}$ Holmes et al ${ }^{15}$ conjugated polylactic acid (PLA) scaffolds with nano-HAP. Their experiments showed that ECs could grow on the surface of the scaffolds, and nano-HAP improved cell adhesion. However, in spite of their use as bone substitute, our understanding of the effects of nano-HAP on ECs remains fragmentary. Recently, the production of nitric oxide (NO) through eNOS activation ${ }^{16,17}$ has often been reported as a mechanism of the growth of ECs, ${ }^{18}$ apoptosis, ${ }^{19}$ migration ${ }^{18,20}$ and angiogenesis, ${ }^{21}$ suggesting a potential role of NO in changes of biological behavior in ECs. Previous studies have shown that NO activation was involved in porous $\beta-\mathrm{CaSiO}_{3} /$ Poly-D,L-LactideGlycolide (PDLGA) composite scaffold-induced increased angiogenic activity of ECs. ${ }^{11}$ Whether NO plays a role in the effect of HANPs on ECs is an interesting issue.

In the current study, HANPs were employed to elucidate their uptake by ECs with a specific focus on internalization pathways and uptake kinetics. In addition, to investigate the direct influence of HANPs on the biological behavior of ECs, we conducted a series of evaluations including cell survival, apoptosis response and angiogenic activity in human umbilical vein ECs (HUVECs) after exposure to HANPs. Furthermore, we also measured levels of $\mathrm{NO}$ and related proteins to determine whether HANPs affect EC functions through the phosphatidylinositol 3-kinase (PI3K)/Akt pathway.

\section{Materials and methods \\ Particles and their characteristics}

Two types of HANPs (20 nm np20 and $80 \mathrm{~nm}$ np80) and one type of micro-sized HAP particles (m-HAP, $12 \mu \mathrm{m}$ ) at $\geq 99.0 \%$ purity were purchased from the Nanjing Emperor Nano Material Company Ltd. (Nanjing, China). The morphologies of HANPs were observed using transmission electron microscopy (TEM; FEI Tecnai G2 Spirit Bio-Twin, FEI, Hillsboro, OR, USA). Fourier transform infrared (FTIR) spectroscopy (Nicolet Nexus870, Thermo Fisher Scientific, Waltham, MA, USA) was used to detect the chemical composition of HAPs. The crystal structures of HAP particles (HAPs) were examined by X-ray diffraction (XRD; Bruker Optik GmbH, Ettlingen, Germany). The hydrodynamic size, surface charge and polydispersibility index of HANPs in EC medium (ECM; Sciencell, Carlsbad, CA, USA) containing 10\% fetal bovine serum (FBS; Sciencell, Carlsbad, CA, USA) were determined using the Zetasizer Nano ZS90 (Malvern Instruments, Malvern, UK). HAPs were sterilized with epoxyethane.

HAPs were labeled via fluorescein isothiocyanate (FITC) to explore cellular uptake. Briefly, $0.05 \mathrm{~g}$ HAPs and $10 \mathrm{~mL}$ 3-aminopropyltriethoxysilane (Sigma-Aldrich Co., St Louis, MO, USA) were mixed in $50 \mathrm{~mL}$ anhydrous ethanol and stirred for $3 \mathrm{~h}$ at $74^{\circ} \mathrm{C}$. Subsequently, $0.025 \mathrm{~g}$ FITC was added into the suspension and allowed to react for $6 \mathrm{~h}$. The treated HAPs were filtered and washed with anhydrous ethanol and ultrapurified water, respectively. FITC-labeled HAPs (FITC-HAPs) were obtained by freezing and lyophilizing.

\section{Cell preparation and culture}

All experimental protocols were approved by the ethics committee of Nanjing Medical University. HUVECs were isolated from the human umbilical cord as previously described, with written informed consent of the donors. ${ }^{22}$ Briefly, the umbilical vein was rinsed thrice with phosphatebuffered saline (PBS) containing $100 \mu \mathrm{g} / \mathrm{mL}$ penicillin and streptomycin (Gibco ${ }^{\circledR}$; Thermo Fisher Scientific, Waltham, MA, USA), digested with $0.1 \%$ collagenase I (Sigma-Aldrich Co.) for $15 \mathrm{~min}$ at $37^{\circ} \mathrm{C}$. After collecting, the cells were cultured in ECM supplemented with 10\% FBS. HUVECs between the third and sixth passages were used in the experiments. Monoclonal antibodies for the von Willebrand factor (vWF; Shanghai ChangDao Biotech Co, Ltd., Shanghai, 
China) were used to confirm the phenotype of the HUVECs by immunofluorescence.

\section{Assessment of cell cycle}

For cell cycle analysis, HUVECs exposed to HAPs were collected after $24 \mathrm{~h}$, washed with PBS and then fixed with 75\% cold ethanol for $24 \mathrm{~h}$ at $-20^{\circ} \mathrm{C}$. Subsequently, HUVECs were washed with PBS and stained with propidium iodide (PI) in RNase at $37^{\circ} \mathrm{C}$ for $30 \mathrm{~min}$. All samples were assessed via flow cytometry (BD Biosciences, San Jose, CA, USA).

\section{Cell viability assay}

Cell viability was evaluated via 3-[4,5-dimethylthiazol-2-yl]5-[3-carboxymethoxyphenyl]-2-[4-sulfophenyl]-2Htetrazolium (MTS), inner salt (Bestbio, Shanghai, China) colorimetric assay. Briefly, HUVECs were seeded in 96-well plates, endocytosis inhibitors were added, and incubated for $30 \mathrm{~min}$, or serial dilutions of HAPs were added and incubated for 24 and $72 \mathrm{~h}$, respectively. The MTS assay was performed following the manufacturer's instructions. The optical density was measured at $490 \mathrm{~nm}$ using a microplate reader (SpectraMax M2; Molecular Devices LLC, Sunnyvale, CA, USA).

\section{Assessment of cell apoptosis}

The percentage of apoptotic cells was determined using the Annexin V-PI apoptosis detection kit (BD Biosciences). Briefly, HUVECs were treated with HAPs for $24 \mathrm{~h}$ and then harvested and washed with PBS. Subsequently, cells were incubated with Annexin V-FITC and PI before the samples were analyzed with a flow cytometer (BD Biosciences).

\section{Uptake activity by TEM and confocal laser scanning microscopy (CLSM)}

TEM and CLSM were used to visualize cellular uptake of HAPs. Briefly, HUVECs were seeded in six-well plates and cultured with $25 \mu \mathrm{g} / \mathrm{mL}$ HANPs for 1,2 and $4 \mathrm{~h}$, respectively. After incubation, HUVECs were collected and fixed by $2.5 \%$ glutaraldehyde to view the uptake and intracellular distribution of HANPs by TEM.

For CLSM imaging, after exposure of HUVECs to $25 \mu \mathrm{g} / \mathrm{mL}$ FITC-HAPs for 1, 2 and $4 \mathrm{~h}$, the cells were fixed with $4 \%$ paraformaldehyde and stained with rhodamine-phalloidin and 4',6-diamidino-2-phenylindole (DAPI). Images were taken with a CLSM (LSM710; Carl Zeiss Meditec AG, Jena, Germany).

\section{Kinetics of HAPs' adhesion and uptake}

The adhesion properties of HAPs to the cell membrane were measured via flow cytometry according to a previous study. ${ }^{23}$ HUVECs in six-well plates were exposed to $25 \mu \mathrm{g} / \mathrm{mL}$
FITC-HAPs for a range of different times at $4^{\circ} \mathrm{C}$. Cells were rinsed twice with PBS and incubated in HAPs-free medium at $37^{\circ} \mathrm{C}$ for $3 \mathrm{~h}$ prior to measurement by flow cytometry.

To quantify the uptake activity of HAPs by HUVECs, the cells in six-well plates were stimulated by $25 \mu \mathrm{g} / \mathrm{mL}$ FITCHAPs for the indicated times at $37^{\circ} \mathrm{C}$. After few washes, HUVECs were fixed by $1 \%$ paraformaldehyde, and the cell fluorescence of HAPs was explored using flow cytometry.

\section{Uptake mechanisms for HAPs in HUVECS}

To clarify uptake routes, internalization of HAPs into HUVECs were examined in the presence of endocytosis inhibitors. Briefly, cells were exposed to $25 \mu \mathrm{g} / \mathrm{mL}$ FITCHAPs for $2 \mathrm{~h}$ after 30 min preincubation with different endocytotic inhibitors, respectively. Three inhibitors were applied in these experiments. ${ }^{24,25}$ Chlorpromazine (cpz) inhibits clathrin-mediated endocytosis. Methyl- $\beta$-cyclodextrin (mßcd) specifically inhibits clathrin- as well as caveolinmediated endocytosis. Cytochalasin D (cytoD) can be used as an inhibitor for actin-dependent phagocytosis and macropinocytosis. Subsequently, images were taken using CLSM and cell fluorescence was quantified by flow cytometry.

\section{Measurement of NO production}

The detection of NO was based on the measurement of the nitrite level using the Griess reagent, containing nitrate reductase. Briefly, after incubation with HAPs for $24 \mathrm{~h}$, the supernatants of HUVECs were collected. Nitrite concentration was quantified by a commercial NO Detection Kit (Beyotime, Shanghai, China) according to the manufacturer's instructions.

\section{Cell migration assays (Transwell)}

Chemotactic motility of HUVECs was assessed using Transwell with $6.5 \mathrm{~mm}$-diameter filters ( $8 \mu \mathrm{m}$ pore size) according to a previous study. ${ }^{26}$ Briefly, ECM (5\% FBS) containing HAPs was added to the lower wells. HUVECs were seeded in the upper chambers and cultured with serum-free ECM. Cells were fixed and stained with $1 \%$ crystal violet after $12 \mathrm{~h}$. Images were captured, and cells that migrated to the lower side of the filter were counted.

\section{Tube formation assay}

In vitro angiogenesis was evaluated by tube formation assay as previously described. ${ }^{27}$ Briefly, ice-cold matrigel (BD Biosciences) was pipetted into a 96-well plate and allowed to solidify at $37^{\circ} \mathrm{C}$ for $1 \mathrm{~h}$. HUVECs were then plated onto the matrigel and incubated with $50 \mu \mathrm{g} / \mathrm{mL}$ HAPs for $8 \mathrm{~h}$. The capillary-like tube formation was viewed with 
an inverted phase contrast microscope (DMI3000B; Leica Microsystems, Wetzlar, Germany) and quantified with the ImageJ analysis software.

\section{Enzyme-linked immunosorbent assay (ELISA)}

To quantify the production of vascular endothelial growth factor (VEGF), media from HUVECs cultured with $50 \mu \mathrm{g} / \mathrm{mL}$ HAPs were collected after $24 \mathrm{~h}$. The amount of VEGF was measured using a commercial Immunoassay Kit (R\&D Systems, Inc., Minneapolis, MN, USA) according to the manufacturer's instructions.

\section{Western blot analysis}

HUVECs were exposed to HAPs for $24 \mathrm{~h}$ and lysed in icecold lysis buffer (Applygen, Beijing, China) for $30 \mathrm{~min}$. Equal amounts of proteins $(40 \mu \mathrm{g})$ were separated by sodium dodecyl sulfate-polyacrylamide gel electrophoresis and transferred onto nitrocellulose membranes (Amersham plc, Amersham, UK). After blocking in 5\% nonfat milk, the membranes were incubated overnight at $4{ }^{\circ} \mathrm{C}$ with antip-Akt, Akt, $\beta$-actin (1:1,000, rabbit polyclonal antibodies;
Cell Signaling Technology, Inc, Danvers, MA, USA), antieNOS (1:500, a rabbit polyclonal antibody; Cell Signaling Technology, Inc) and anti-p-eNOS (1:1,000, a rabbit monoclonal antibody; Cell Signaling Technology, Inc), washed with Tris-buffered saline (TBS) containing $0.05 \%$ Tween-20 (TBST) and incubated with appropriate horseradish peroxidase-conjugated secondary antibodies for $1 \mathrm{~h}$ at room temperature. Immunoreactive bands were detected using chemiluminescence gel imaging system (LAS4000M; GE Healthcare Bio-Sciences AB, Uppsala, Sweden).

\section{Statistical analysis}

Data were expressed as mean \pm SD of three separate experiments. Statistically significant differences $(P<0.05)$ among the groups were determined using one-way ANOVA. All statistical analysis was conducted using SPSS 18.0 software (SPSS Inc., Chicago, IL, USA).

\section{Results \\ Characterization of HAPs}

As shown in Figure 1A1 and A2, the TEM images of HANPs confirmed that np20 particles were near-spherical with
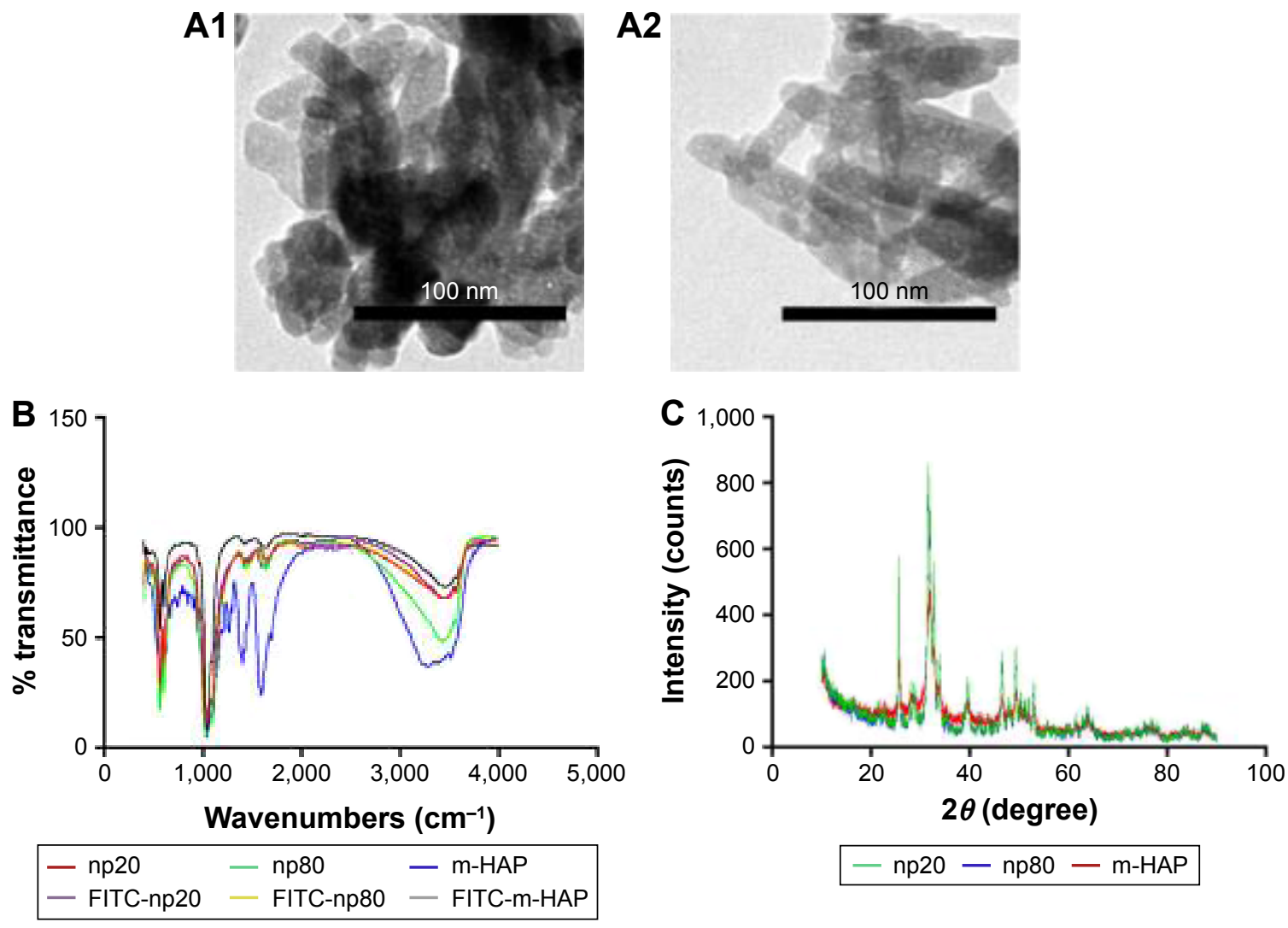

Figure I Characteristics of HAPs.

Notes: TEM micrographs of np20 (AI) and np80 (A2). FTIR patterns (B) and XRD patterns (C).

Abbreviations: FITC, fluorescein isothiocyanate; FTIR, Fourier transform infrared; HAP, hydroxyapatite; m-HAP, micro-sized HAP particles; TEM, transmission electron microscopy; XRD, X-ray diffraction. 
approximate diameters of $20 \mathrm{~nm}$, while $\mathrm{np} 80$ particles were rod like, $\sim 20 \mathrm{~nm}$ in width and $\sim 80 \mathrm{~nm}$ in length.

The FTIR spectra (Figure 1B) of HAPs and FITC-HAPs featured phosphate absorption bands. The asymmetric stretching and bending vibrations of characteristic phosphate $\left(\mathrm{PO}_{4}^{3-}\right)$ were at 1,030 and $565 \mathrm{~cm}^{-1}$, respectively, while the peaks at 3,445.79 and $1,639 \mathrm{~cm}^{-1}$ indicated remaining water. In addition, the peaks at 1,420 and $876 \mathrm{~cm}^{-1}$ corresponded to $\mathrm{CO}_{3}{ }^{2-}$, indicating incorporation of carbonate ions, which is a common phenomenon during the fabrication of HAPs.

The representative XRD patterns (Figure 1C) of three types of HAPs showed that their diffraction peaks matched with the typical pattern of the standard HAP (JCPDS090432) and no other phases were found, indicating high purity. The hydrodynamic sizes of np20 and np 80 , as estimated by dynamic light scattering, were 108.8 and $309.6 \mathrm{~nm}$, respectively. The polydispersibility indexes were 0.307 and 0.264 for np20 and np80, respectively, suggesting that these HANPs were well dispersed in the ECM. The results of zeta-potential indicated that the HANPs presented a negative surface charge in ECM (Table 1).

\section{Effect of HAPs on cell cycle}

Treatment of HUVECs with HANPs (50,100 and $200 \mu \mathrm{g} / \mathrm{mL}$ ) and m-HAP (100 and $200 \mu \mathrm{g} / \mathrm{mL})$ significantly increased the cell population in the $\mathrm{G} 2$ and $\mathrm{S}$ phases $(P<0.05)$; however, no dose effect was observed in three groups (Figure $\mathrm{S} 1$ ).

\section{Effect of HAPs on cell viability}

To assess the effect of HAPs on cell metabolic activity, cell viability was assayed. As shown in Figure 2A1-A3, cell viability progressively decreased in a dose-dependent manner, and the effects of HANPs on cell viability were more obvious than that of m-HAP. Significant difference of cell viability was observed when incubated with 50, 100 and $200 \mu \mathrm{g} / \mathrm{mL}$ HANPs for 24 and $72 \mathrm{~h}$ compared to control, while after treatment with np20 and np 80 at $200 \mu \mathrm{g} / \mathrm{mL}$ for $72 \mathrm{~h}$, cell viability decreased to approximately $20 \%$ of control. In comparison, only the highest concentrations of m-HAP $(200 \mu \mathrm{g} / \mathrm{mL})$ resulted in a significant decrease in cell viability $(P<0.01)$ at both time points.

Table I Characterization of the particle parameters of HANPs

\begin{tabular}{llll}
\hline Material & $\begin{array}{l}\text { Hydrodynamic } \\
\text { diameter in ECM } \\
\text { with 10\% FBS (nm) }\end{array}$ & $\begin{array}{l}\text { Zeta-potential } \\
\text { in ECM with } \\
\text { I0\% FBS (mV) }\end{array}$ & $\begin{array}{l}\text { Polydispersibility } \\
\text { index }\end{array}$ \\
\hline $\mathrm{np} 20$ & 108.8 & -10.6 & 0.307 \\
$\mathrm{np} 80$ & 309.6 & -9.65 & 0.264 \\
\hline
\end{tabular}

Abbreviations: ECM, endothelial cell medium; FBS, fetal bovine serum; HANPs, hydroxyapatite nanoparticles.

\section{Apoptosis and necrosis triggered by HAPs}

To further explore the biological impact of HAPs on HUVECs, apoptosis and necrosis in HUVECs were evaluated. As depicted in Figure 2B, HUVECs' exposure to HAPs $(25,50,100$ and $200 \mu \mathrm{g} / \mathrm{mL})$ did not show any significant change in necrosis. Moreover, no significant difference of apoptosis was detected when incubated with np20 and m-HAP for $24 \mathrm{~h}$ compared to control $(P>0.05)$; in comparison, HUVECs exposed to 100 and $200 \mu \mathrm{g} / \mathrm{mL}$ np 80 for $24 \mathrm{~h}$ showed a significant increase in apoptotic rate as compared to control (Figure 2C).

\section{Uptake of HAPs by HUVECs}

A comprehensive investigation on cellular uptake would contribute to a clearer understanding of the biological impact that NPs may exert. As shown in Figures 3 and 4, HANPs first adhered to cell membrane, then entered cells. HANPs either located in the cytoplasmic vesicles or were distributed like cluster in the cytoplasm of the HUVECs and did not enter the cell nucleus. With prolonged incubating time, more HANPs were uptaken by HUVECs, which caused nucleus deformation, condensed chromatin, mitochondrial swelling and a large number of vacuoles that occurred within the cytoplasm (Figure 3B4, B7 and B8). Furthermore, the cytoskeletons were not clear and the cell edges were crimped. However, only a small number of m-HAP were observed in cells during the observation, and they did not significantly affect cellular morphology compared to HANPs (Figure 4).

\section{Kinetics of HAPs' adhesion and uptake}

To quantify HAPs' adhesion and uptake, their kinetics were examined. Figure 5A shows the adhesion of HANPs to the cell membrane of HUVECs as a function of time. Within the first $30 \mathrm{~min}$, almost no change in the adsorbed amount was detected, and this observation held true for all groups. Then, the adsorption of HANPs slowly increased, while after 180 min they reached a dynamic equilibrium. By contrast, cell fluorescence of m-HAP remained nearly constant with time, and it was lower than that of HANPs.

As indicated in Figure 5B, in the np20 and np 80 groups, the uptake kinetics showed a similar characteristic to an initial transient, followed by a rapid increase in the cell fluorescence signal with time. After $60 \mathrm{~min}$, a relatively steady state was reached. In comparison to $\mathrm{np} 20$, the uptake speed of np80 was slower; however, the fluorescence was higher when the equilibrium was reached. Clearly, cell fluorescence of 

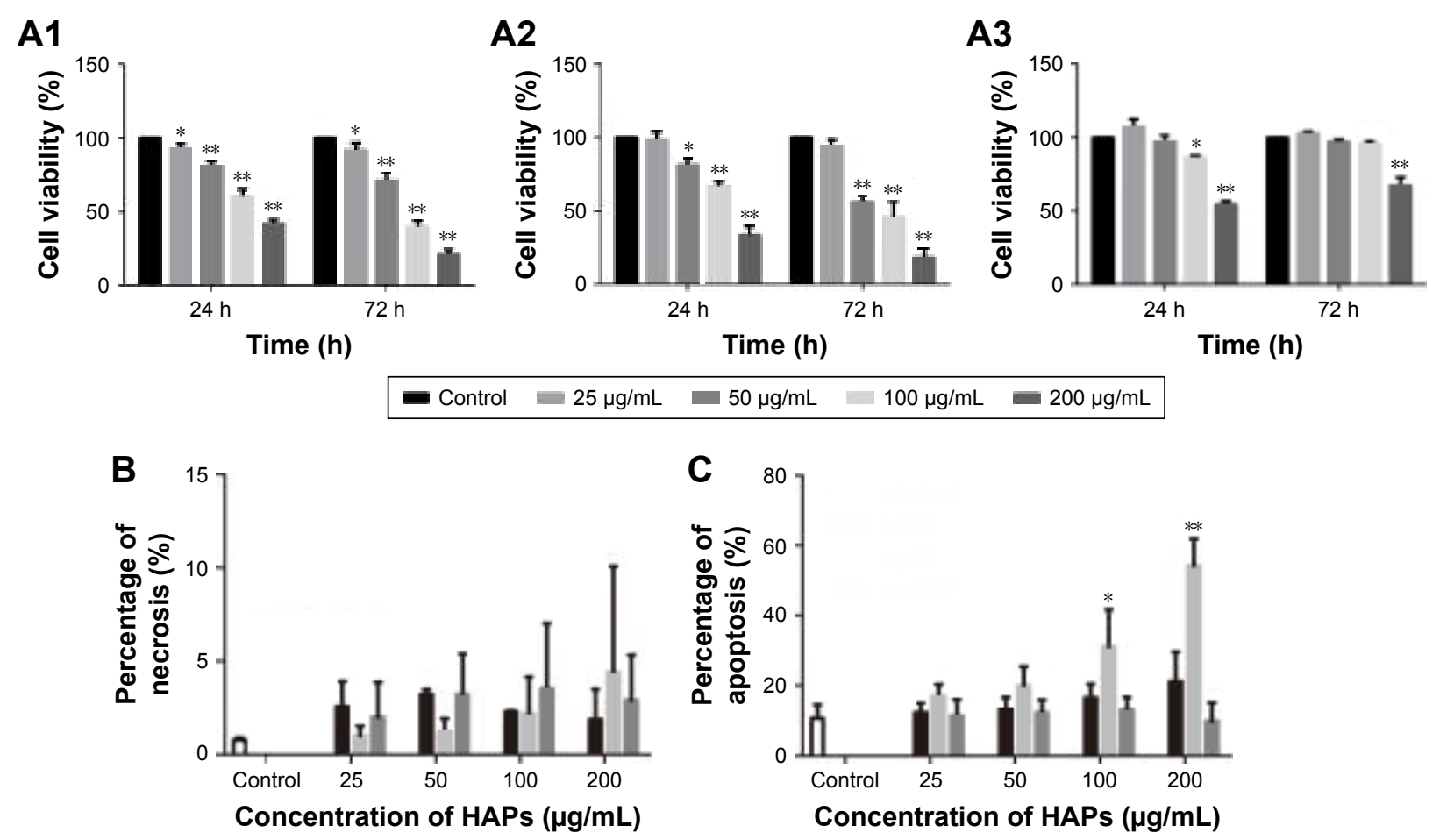

$\square$ Control $\square \mathrm{np20} \quad \mathrm{np80} \quad \mathrm{m}-\mathrm{HAP}$

Figure 2 Effects of HAPs on cell viability and apoptosis.

Notes: The viability of HUVECs cultured with np20 (AI), np80 (A2) and m-HAP (A3) for 24 and 72 h. A subpopulation of necrotic (B) and apoptotic cells (C) following HAP treatment for $24 \mathrm{~h} . * \mathrm{P}<0.05 ; * * P<0.0$ I versus control. Cells without HAP treatment were set as the control group.

Abbreviations: HAP, hydroxyapatite; HUVECs, human umbilical vein endothelial cells; m-HAP, micro-sized HAP particles.

m-HAP was much lower compared to HANPs, and it slightly increased during the observation.

\section{The activation of internalization pathways in HUVECs by HAPs}

To determine the cytotoxicity of endocytosis inhibitors on HUVECs in vitro, cell viability was measured using the MTS assay. As depicted in Figure S2, after treatment with cpz, $\mathrm{m} \beta \mathrm{cd}$ and cytoD, the viability of HUVECs slightly decreased to $81.6 \%, 92.91 \%$ and $92.33 \%$, respectively.

Having established that the HANPs could be uptaken by HUVECs, we investigated the endocytic pathways involved in the regulation of internalization. As shown in Figure 6, for $\mathrm{cpz}$, mild reduction of cell fluorescence was observed in all groups; however, the decrease in np 80 was not significant compared to that of no inhibitor group. The addition of $\mathrm{m} \beta \mathrm{cd}$ significantly suppressed cell fluorescence of HAPs, especially for np20 and np80 (by about 50\% less as compared to no inhibitor samples). CytoD also resulted in noticeably fewer HAPs' uptake activity, and the cell fluorescences in np20, np80 and m-HAP decreased to $73 \%, 52 \%$ and $26 \%$, respectively. Moreover, we found that cell viability slightly decreased in the presence of three inhibitors (Figure S2).

\section{Effect of HAPs on HUVEC function}

To understand the interactions of HAPs with HUVECs, cell migration, tube formation and VEGF secretion were explored. As indicated in Figure 7A and B, HANP treatment significantly decreased HUVEC migration in a dose-dependent manner compared to m-HAP and control; moreover, the migratory activity of HUVECs cultured with np20 was higher than that for np80 $(P<0.01)$, while there was no significant difference between m-HAP and control. We further examined the effect of HAPs on VEGF production, and as shown in Figure 7C, np20 induced VEGF secretion slightly $(P<0.05)$; however, there were no remarkable differences among the remaining three groups $(P>0.05)$. Consistent with these results, HANPs suppressed tube formation at a concentration of $50 \mu \mathrm{g} / \mathrm{mL}$, especially for np80 (Figure 7D and E).

\section{The inhibition of eNOS through the Akt- dependent pathway in HUVECs by HAPs}

To explore the role of NO in effects of HANPs on ECs, we examined NO release. There was a decrease in NO production with increasing concentrations of HAPs; moreover, np80 resulted in the most significant decrease in NO production, with the highest concentration $(100 \mu \mathrm{g} / \mathrm{mL})$ giving rise to 


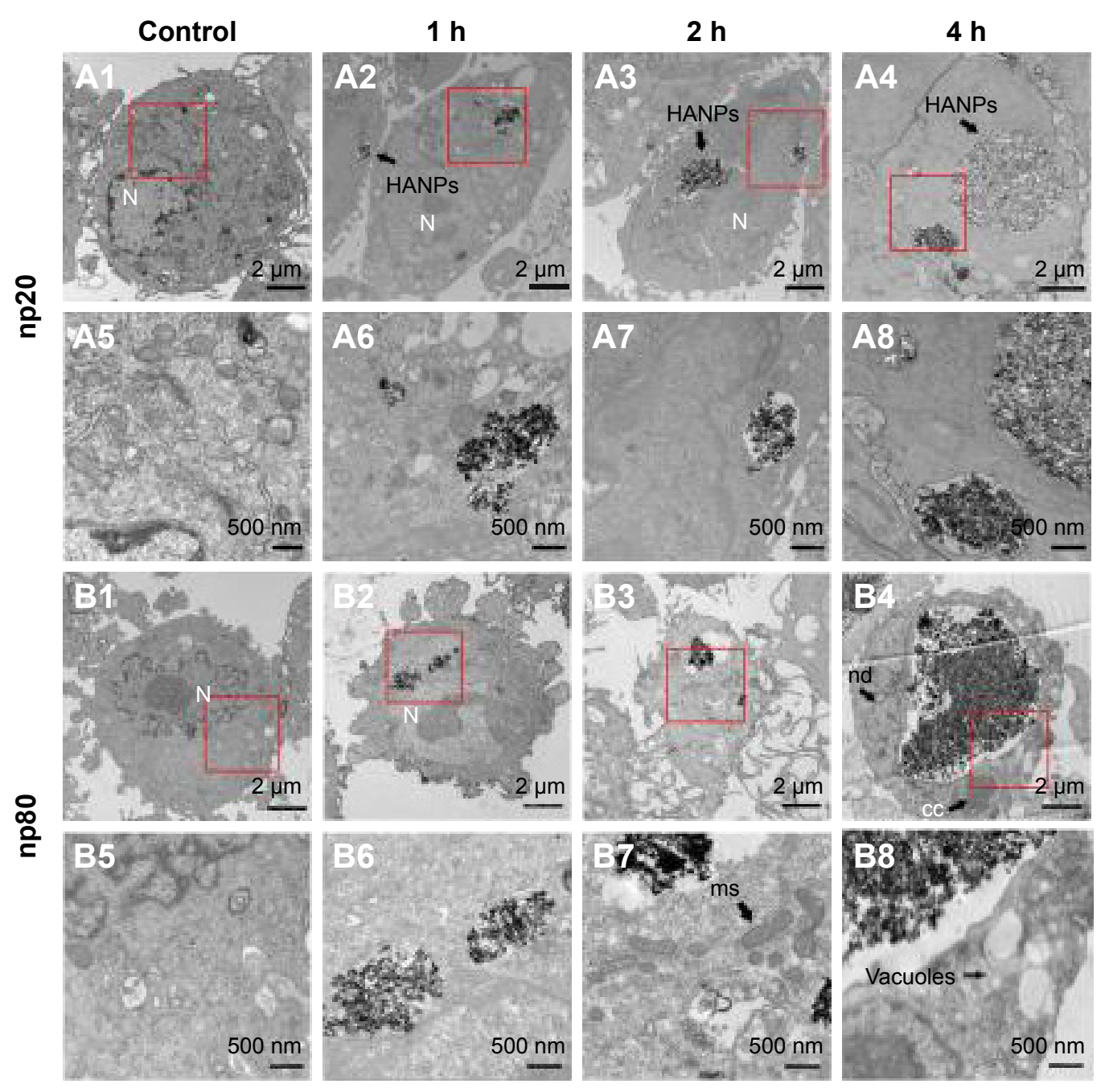

Figure 3 TEM micrographs of internalization and intracellular distribution of HANPs in HUVECs exposed for I, 2 and $4 \mathrm{~h}$.

Notes: HUVECs without any treatment (AI, A5, BI and B5); HUVECs treated with np20 (A2-A4 and A6-A8) and np80 (B2-B4 and B6-B8). Overall cell morphology (AI-A4 and B I-B4), scale bar: $2 \mu \mathrm{m}$. Higher magnification of cells in red boxed areas (A5-A8 and B5-B8). Scale bar: $500 \mathrm{~nm}$.

Abbreviations: N, nucleus; cc, condensed chromatin; HANPs, hydroxyapatite nanoparticles; HUVECs, human umbilical vein endothelial cells; ms, mitochondrial swelling; nd, nucleus deformation; TEM, transmission electron microscopy.

an approximately $60 \%$ decrease. Comparing samples treated with $25 \mu \mathrm{g} / \mathrm{mL}$ m-HAP and np20, no significant difference of NO expression was observed, while at doses up to 50 and $100 \mu \mathrm{g} / \mathrm{mL}$ NO production was significantly higher in m-HAP $(P<0.01$; Figure $8 \mathrm{~B})$. We next determined whether HAPs reduced NO production through a PI3K/Akt-dependent eNOS pathway in ECs. As depicted in Figure 8A1-A3, the effects of HAPs to reduce NO production were associated with a decrease in p-eNOS expression in HUVECs. In comparison to control, phosphorylation of Akt and eNOS was diminished in a dose-response manner when HUVECs were cultured with HAPs for $24 \mathrm{~h}$, whereas the expression of total Akt and eNOS remained unaltered. Furthermore, as shown in Figure 8C and D, the decrease in NO production and cell viability was effectively restored by the PI3K activator IGF-1.

\section{Discussion}

With the rapid technological advancement in biomaterials, artificial bone substitutes have provided a promising and practical alternative approach for bone repair. Consequently, the interaction of biological systems such as living cells with bone grafting materials has become a fascinating area of regenerative medicine. Evidence is accumulating implying that nano-HAP may serve as a bone substitute and may exert beneficial effects on bone regeneration. ${ }^{7,28,29}$ However, the internalization profile of HANPs in ECs, and potential health effects that may be introduced by HANPs, especially on the functions of vascularization is far from being completely understood. A comprehensive investigation on the biological responses that HANPs may elicit would contribute to explore its potential for bone repair and help to devise strategies to minimize related risks. 

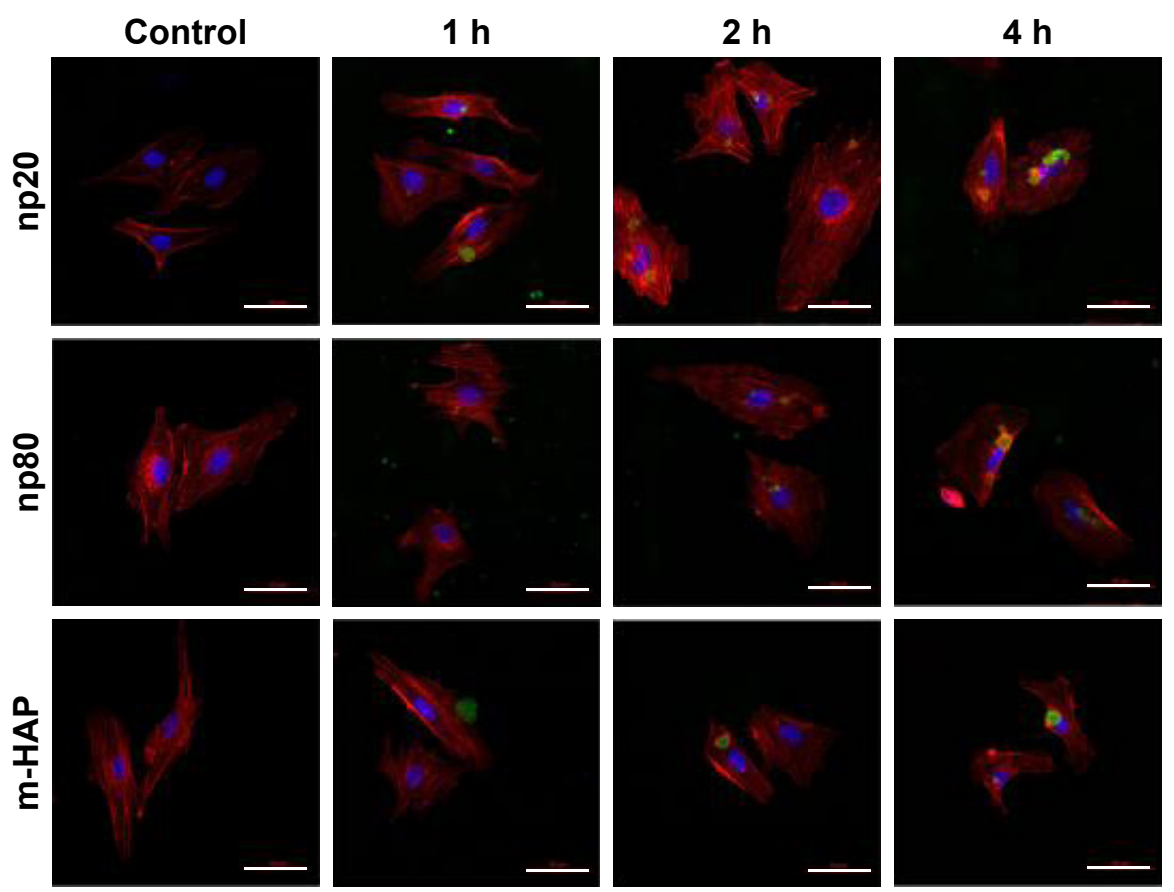

Figure 4 CLSM micrographs of internalization and subcellular distribution of HAPs in HUVECs exposed for I, 2 and 4 h.

Notes: Cells stained for nuclei (blue) and actin (red). HAPs are shown in green. Scale bar: $50 \mu \mathrm{m}$.

Abbreviations: CLSM, confocal laser scanning microscopy; HAP, hydroxyapatite; HUVECs, human umbilical vein endothelial cells; m-HAP, micro-sized HAP particles.

The evaluation of cellular compatibility is a preliminary step in assessing the biological behavior of biomaterial. In our study, exposure to both types of HANPs caused a decline in cell viability and elevated apoptosis with increasing HANP concentration (Figure 2A and C), and the HANPs $(50-200 \mu \mathrm{g} / \mathrm{mL})$ also triggered a slight increase in cell population in $\mathrm{S}$ and $\mathrm{G} 2$ phases, compared to the control group (Figure S1). The cytotoxic effect of np20 and np80 on HUVECs could be attributed to the induction of oxidative stress by HANPs as well as elevated intracellular calcium concentration due to substantial uptake of HANPs (Figures 3-5). ${ }^{30,31}$ To date, the cytotoxicity of HANPs still remains a matter of debate. It has also been reported that HANPs were compatible to mouse bone marrow mesenchymal stem cells. ${ }^{32}$ This might be partly due to the different cell type. Increasing evidence in the literature indicated that cytotoxicity of NPs was cell dependent. ${ }^{33}$ Zhao et al $^{34}$ synthesized HANPs of four different shapes - needle (nano-HAP-ND), plate (nano-HAP-PL), sphere (nano-HAP-SP) and rod (nanoHAP-RD) - and recorded the most significant induction of
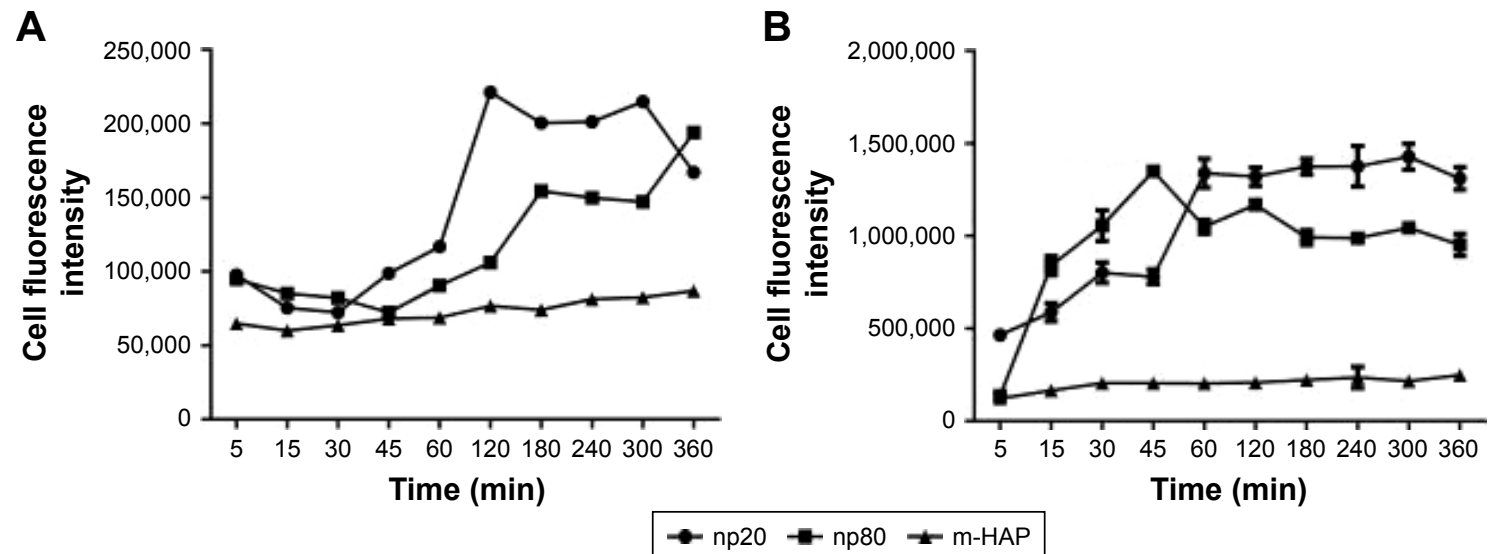

Figure 5 Kinetics of HAPs' adhesion and uptake.

Notes: Kinetics of adhesion of HAPs onto HUVECs (A). Kinetics of uptake of HAPs by HUVECs (B).

Abbreviations: HAP, hydroxyapatite; HUVECs, human umbilical vein endothelial cells; m-HAP, micro-sized HAP particles. 

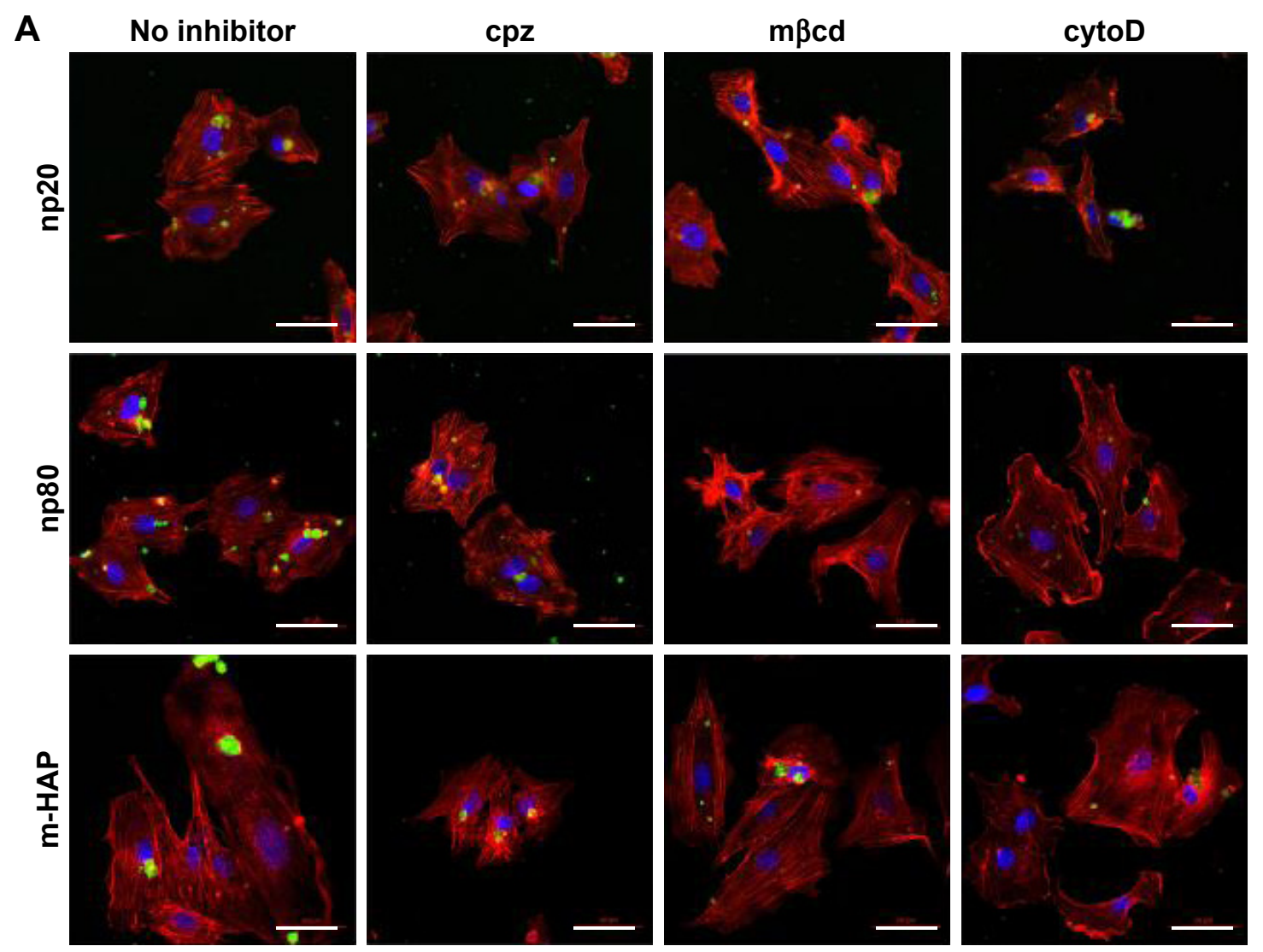

$\mathbf{B}$

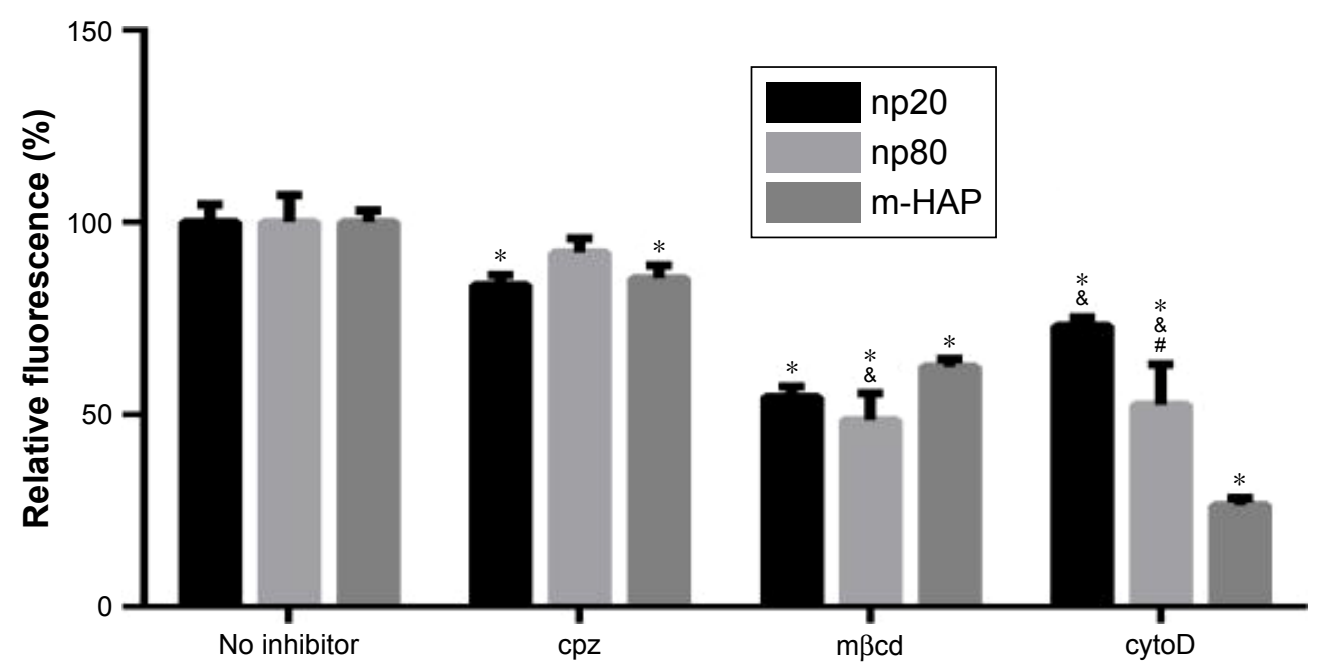

Figure 6 The role of different endocytic pathways in the uptake of HAPs in HUVECs.

Notes: Cells were exposed to HAPs either with or without cpz, $\mathrm{m} \beta c d$ and cytoD. (A) CLSM images of HAP interactions with HUVECs for $2 \mathrm{~h}$. Cells stained for nuclei (blue) and actin (red). HAPs are shown in green. Scale bar: $50 \mu \mathrm{m}$. (B) Quantification of the uptake of HAPs after HUVECs were treated with HAPs for $2 \mathrm{~h}$. *P $<0.0 \mathrm{I}$ versus no inhibitor control, ${ }^{\&} P<0.01$ versus $m-H A P$ group, ${ }^{\#} P<0.01$ versus $n p 20$ group.

Abbreviations: CLSM, confocal laser scanning microscopy; cpz, chlorpromazine; cytoD, cytochalasin D; HAP, hydroxyapatite; HUVECs, human umbilical vein endothelial cells; $\mathrm{m} \beta \mathrm{cd}$, methyl- $\beta$-cyclodextrin; m-HAP, micro-sized HAP particles.

cell death by nano-HAP-ND and nano-HAP-PL in BEAS-2B cells; nevertheless, no significant cell death was noted in RAW264.7 cells treated with any of the nano-HAPs. Yuan et $\mathrm{al}^{35}$ also found HANPs had little impact on the cell viability of human L-02 cells; however, in human hepatoma HepG2 cells, HANPs caused distinct growth inhibition and apoptosis. However, our results were contrary to a report by Pezzatini et al, who suggested that HAP nanocrystals did not induce any cytotoxic effect on ECs. ${ }^{14}$ A possible reason was that the dose used in their research was lower $(10 \mu \mathrm{g} / \mathrm{mL})$, which 
A

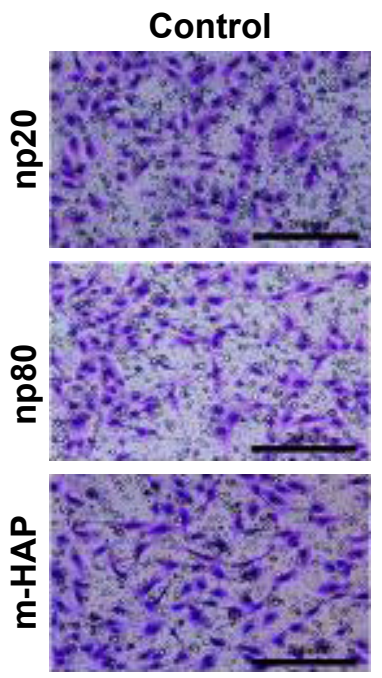

B

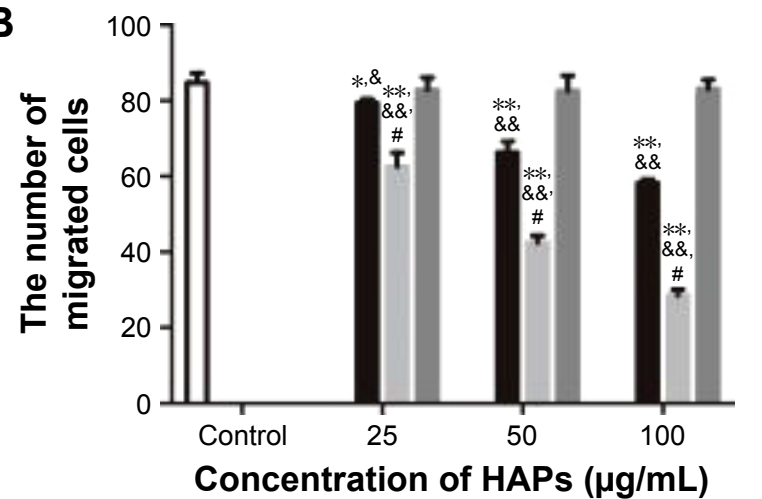

$25 \mu \mathrm{g} / \mathrm{mL}$
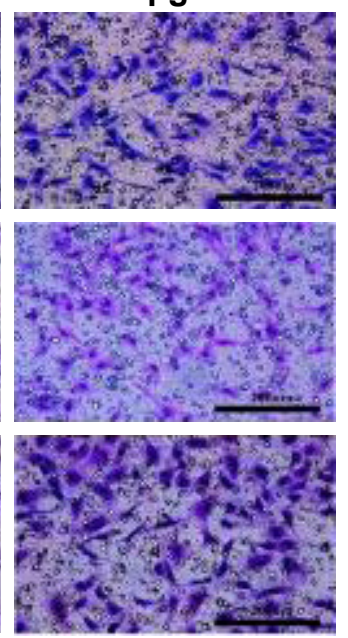

$50 \mu \mathrm{g} / \mathrm{mL}$
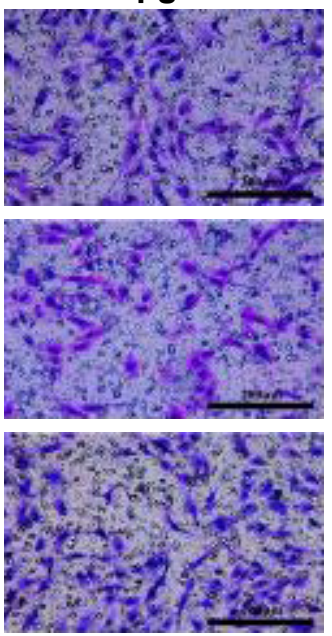

$100 \mu \mathrm{g} / \mathrm{mL}$

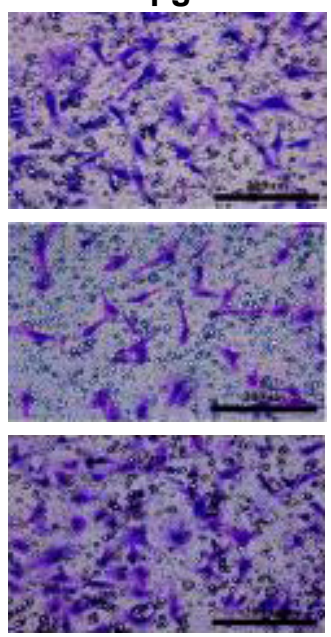

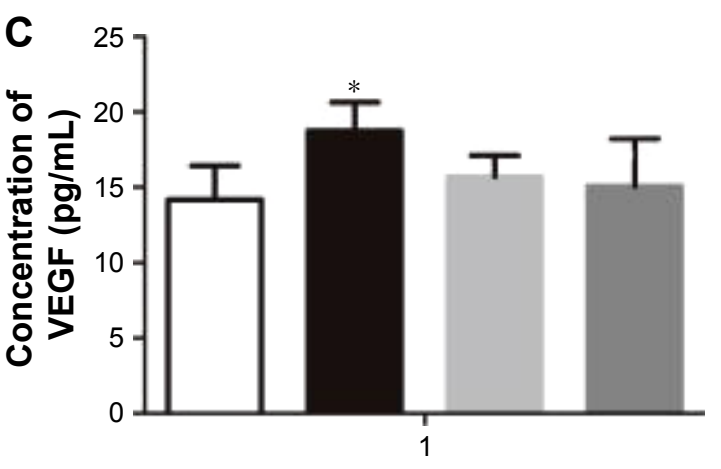

Days in culture

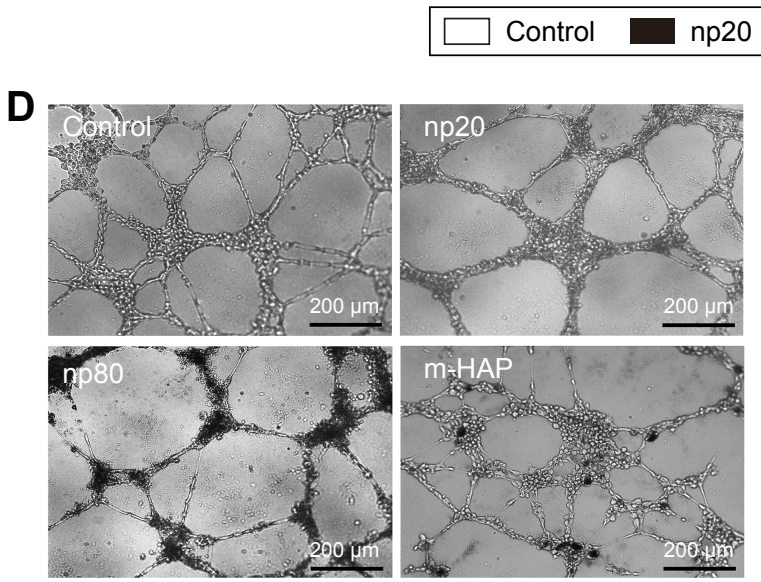

np80 m-HAP

E

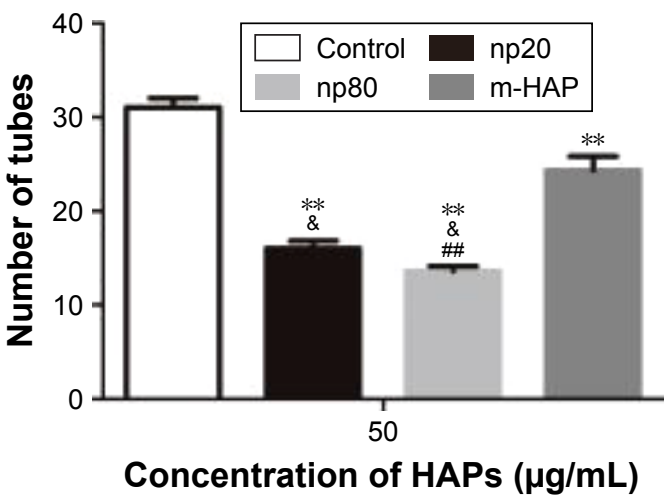

Figure 7 Effects of HAPs on HUVEC function.

Notes: (A and B) Images and quantification of migrated cells treated with HAPs in Transwell plates for $12 \mathrm{~h}$. (C) VEGF secretion of HUVECs cultured with HAPs for $24 \mathrm{~h}$. (D and E) Micrographs and quantification of tube-forming activity in HUVECs cultured with HAPs for 8 h. Cells without HAP treatment were used as the control group.

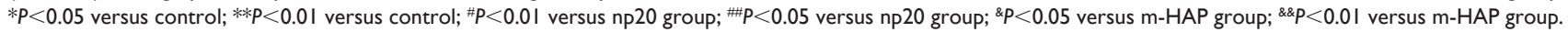
Abbreviations: HAP, hydroxyapatite; HUVECs, human umbilical vein endothelial cells; m-HAP, micro-sized HAP particles.

may probably account for the different effects of HANPs on the same cells.

Given the key role of nanomaterial internalization and subcellular localization toward biological outcomes, we investigated the uptake profile and biodistribution of HAPs.
The results revealed that HANPs could be transported into HUVECs, and no evidence of HAPs entering the cell nucleus could be found (Figures 3 and 4). A previous study has indicated that the HANPs, only within the cell nucleus, could induce cytotoxicity, while the HANPs that remained 

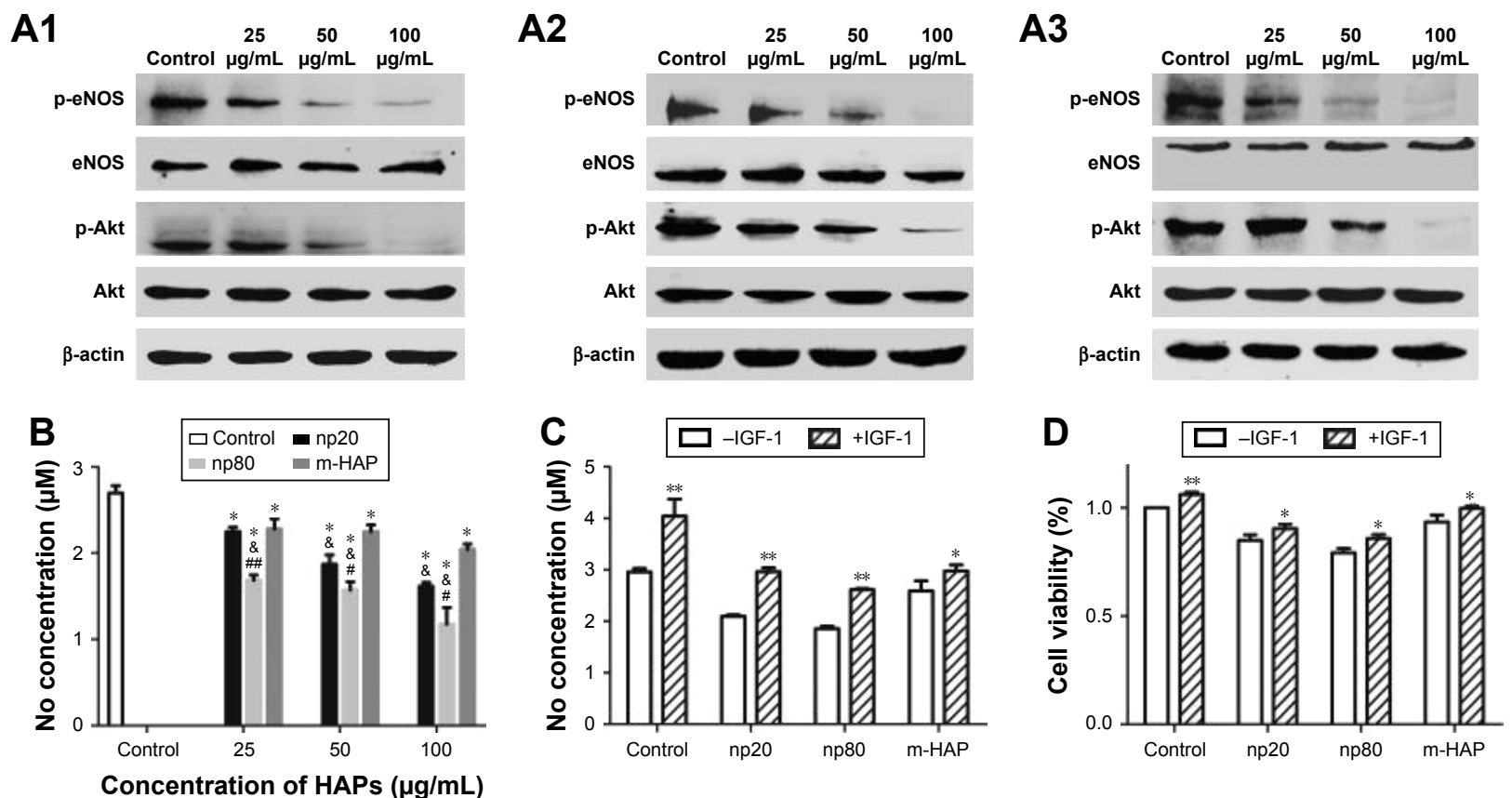

Figure 8 HAPs suppress angiogenesis through the inhibition of PI3K/Akt-dependent eNOS/NO pathway.

Notes: The expression profile of key proteins in the PI3K/Akt/eNOS pathway in HUVECs cultured with np20 (AI), nP80 (A2) and m-HAP (A3) for 24 h. (B) NO levels of HUVECs incubated with HAPs for $24 \mathrm{~h}$. ${ }^{*} P<0.0$ I versus control, ${ }^{\circledR} P<0.01$ versus $m$-HAP group, ${ }^{\#} P<0.05$; ${ }^{\#} P<0.01$ versus np20 group. Cells without HAPs treatment were set as the control group. (C) NO levels and (D) cell viability of HUVECs exposed to HAPs in the presence or absence of IGF-I, respectively. $* P<0.05$; $* * P<0.0$ I versus vehicle control.

Abbreviations: HAP, hydroxyapatite; HUVECs, human umbilical vein endothelial cells; m-HAP, micro-sized HAP particles; NO, nitric oxide.

in the perinuclear region or cytoplasm only caused local modifications to the morphology and structure of the cell membrane and exerted negligible inhibitory effects. ${ }^{35,36,37}$ However, our results suggested that HANPs might interact with organelles, such as chondriosome and lysosomes (Figure 3), thus interfering with HUVEC survival and function although they concentrated in the cytoplasm (Figures 2 and 7). The uptake of NPs originated from an event of NPs adhering to the cell membrane, and this process was followed by the actual internalization via energy-dependent uptake pathways. ${ }^{38,39}$ Thus, there is a direct link between the uptake efficiency of NPs and initial adhesion of NPs to cells. Nevertheless, it is difficult to assess the adhesion profile of NPs to the cell membrane in the presence of simultaneous internalization. At $4^{\circ} \mathrm{C}$, the uptake of NPs had been shut down; ${ }^{40,41}$ therefore, it was possible to reproduce and quantify the adhesion of NPs to cell membrane by following the exposure to NPs at $4^{\circ} \mathrm{C}$ with an incubation in $\mathrm{NP}$-free medium at $37^{\circ} \mathrm{C}$ prior to evaluation. ${ }^{23}$ In this way, we found that although the number of HANPs adhering to the cell membrane was lower as compared to the number of HANPs inside HUVECs, similar trends were observed in their kinetics, suggesting the adhesion profile of HANPs as important determinants of uptake rates of HANPs.
In this work, it was noted that the spherical np20 exhibited higher internalization than the rod-shaped np80, while Motskin et $\mathrm{al}^{42}$ demonstrated enhanced ingestion of rodshaped HANPs compared to spherical HANPs in human monocytes-derived macrophages. These observations collectively shed light on the fact that cellular uptake of NPs is highly dependent on cell type and further affected by particle size and shape. Another interesting result of our study was the unusual correlation between cellular uptake and biological responses caused by HANPs. Some previous data indicated a direct link between cytotoxicity and particle-cell association. ${ }^{43,44}$ However, our results revealed that np20 showed higher uptake, while more significant inhibitory effects on the ECs function were detected upon incubation with np80 (Figures 5B and 7), implying cellular uptake was not the only determinant of biological outcome; other factors, such as shape, may be involved in the interaction. Indeed, elegant experiments have demonstrated the significant role of the shape of NPs in the bioactivity. ${ }^{34}$

Since we have shown that HANPs could be internalized by HUVECs, it is interesting to determine their endocytosis pathway during the process. It is well accepted that several endocytic pathways, such as clathrin- and caveolin-mediated endocytosis as well as macropinocytosis, are involved in the 
internalization of NPs. ${ }^{45}$ Recent investigations have suggested that caveolae-mediated endocytosis is an important pathway that transports gold NPs and polystyrene NPs into ECs. ${ }^{46-48}$ In this study, the results showed that HAPs were less uptaken in the presence of $\mathrm{cpz}, \mathrm{m} \beta \mathrm{cd}$ and cytoD, but to a different degree (Figure 6). For np20 and np80, m $\beta c d$ had the most obvious inhibitory effects, followed by cytoD, implying clathrin- and caveolin-mediated endocytosis as the crucial internalization pathways that HANPs enter HUVECs, and actin-dependent macropinocytosis also played an important role in the process. This might be partly due to HANP agglomeration. In comparison, the inhibitory effect of cytoD on m-HAP was most significant, which was a good indication that m-HAP were mainly uptaken through macropinocytosis, and these findings corresponded with reports describing that ingestion of particles above $500 \mathrm{~nm}$ size typically occurred via triggered macropinocytosis or phagocytosis. ${ }^{45}$ According to previous studies, caveolin-mediated endocytosis-formed caveolaes have an average size of about $120 \mathrm{~nm}$, and the average size of clathrin-mediated endocytosis-formed vesicles was about $150-200 \mathrm{~nm}^{45,49}$ These are smaller than the size of our m-HAP; however, it is noteworthy that our observations showed that clathrin- and caveolin-mediated endocytosis were also implicated in the internalization of m-HAP in HUVECs. Further investigations are indispensable in this study. In summary, these results indicated that the uptake of NPs via different endocytic pathways was highly dependent on cell- and material type, while the size of NPs was not the only thing that mattered, and it was likely that several endocytic pathways acted synergistically in the internalization of HAPs in HUVECs.

The internalization of HANPs in HUVECs raised our concern about the influence of HANPs on angiogenesis. The migration and capillary-like tube formation of ECs play a key role in vascular remodeling and regeneration. ${ }^{50}$ In this study, unexpectedly, we observed a decrease in migration of HUVECs with increasing concentrations of HANPs (Figure 7A and B), and this trend was also observed in the experiment of tube formation (Figure 7D and E). Our findings were in agreement with a recent study showing that HUVECs cultured on pure PLA scaffolds exhibited larger and more highly developed vascular structures compared to those on the nano-HAP-conjugated scaffolds. ${ }^{15}$ These observations collectively indicated a negative effect of HANPs on the function of ECs. The biological responses of HANPs may be the results of either their direct impacts on ECs or via the modulation of other factors, such as VEGF, which is a wellknown angiogenic factor. ${ }^{51}$ To validate this possibility, the expression of VEGF in HUVECs was evaluated. Treatment with np20 triggered up to a mild increase in expression level of VEGF. Conversely, no significant change in the expression of VEGF was observed in the np 80 and m-HAP groups (Figure 7C). These results suggested that the effects of HANPs on HUVEC function do not exert by the modulation of VEGF expression, indicating HANPs may act as a direct negative regulator of ECs. Synthesis of NO, under the regulation of the eNOS, ${ }^{16,17}$ plays an essential role in the maintenance of EC homeostasis, reparative vasculogenesis and postnatal angiogenesis. ${ }^{21,52,53}$ In this context, we investigated whether NO might participate in the influence of HAPNs on ECs. As expected, we observed a concentration-dependent decline in NO production when cells were treated with HAPs, and the overall results were in line with the trends seen in cell migration and tube formation (Figure 8B). To gain further insights into the mechanism by which HANPs could possibly impair angiogenic function in ECs, we examined the PI3K/Akt/eNOS pathway that had been demonstrated to exert a marked impact on endothelial repair and regeneration while actively stimulating postnatal neovascularization and reparative vasculogenesis. ${ }^{54,55}$ Specifically, previous investigations have revealed that nanocomposites and cytokine could regulate the function of ECs via this mechanism..$^{16,56}$ In the current study, we made the novel observation that HAPs suppressed phosphorylation of eNOS remarkably and in a dose-dependent manner, and the suppression of p-eNOS paralleled the downregulation of p-Akt by HAPs (Figure 8A). In addition, the HAPs-inhibited NO production and cell viability of HUVECs could significantly be restored via treatment with IGF-1, a specific PI3K/Akt activator (Figure 8C and D). These observations collectively suggested that HAPs might serve to regulate EC function through the PI3K/Akt/ eNOS signaling (Figure 9).

\section{Conclusion}

To deeply comprehend the bioactivity and biocompatibility of nano-HAP as bone graft substitution, using commercially available HANPs (20 and $80 \mathrm{~nm}$ ) as model, we investigated the interaction of HANPs with ECs in terms of uptake and impacts on the function of cells in HUVECs. Compared to m-HAP, a large amount of HANPs adhered to the cell membrane and were subsequently uptaken by HUVECs mainly through clathrin- and caveolin-mediated endocytosis. HANPs were distributed in the cytoplasm and not detected in the nucleus. However, only a small number of m-HAP could get into HUVECs mainly via macropinocytosis. Furthermore, we made the novel observation that HANPs distinctly inhibited the angiogenic ability of HUVECs in a dose-dependent manner. This might be induced by reducing NO synthesis 


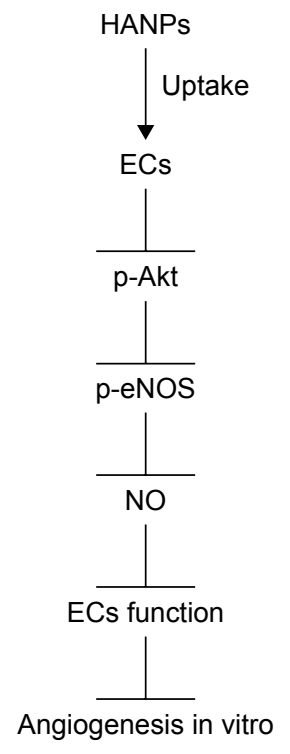

Figure 9 A schematic graph of the possible mechanisms. Abbreviations: ECs, endothelial cells; HANPs, hydroxyapatite nanoparticles; NO, nitric oxide.

and phosphorylation of eNOS protein in HUVECs via the $\mathrm{PI} 3 \mathrm{~K} / \mathrm{Akt}$ pathway. These findings collectively suggested that further studies about the nature of interaction of nano-HAP with biological systems are required before they can be used for bone reconstruction.

\section{Acknowledgments}

This work was supported by grants from the National Natural Science Foundation of China (No 81300913), the Natural Science Foundation of the Jiangsu Higher Education Institutions of China (No 13KJB320007), the Natural Science Foundation of Jiangsu Province of China (No BK20161566), and a Project Funded by the Priority Academic Program Development of Jiangsu Higher Education Institutions (No 2014-37).

\section{Disclosure}

The authors report no conflicts of interest in this work.

\section{References}

1. Prakasam M, Locs J, Salma-Ancane K, Loca D, Largeteau A, Berzina-Cimdina L. Fabrication, properties and applications of dense hydroxyapatite: a review. J Funct Biomater. 2015;6(4):1099-1140.

2. Deepthi S, Venkatesan J, Kim SK, Bumgardner JD, Jayakumar R. An overview of chitin or chitosan/nano ceramic composite scaffolds for bone tissue engineering. Int J Biol Macromol. 2016;93(pt B):1338-1353.

3. Brie IC, Soritau O, Dirzu N, et al. Comparative in vitro study regarding the biocompatibility of titanium-base composites infiltrated with hydroxyapatite or silicatitanate. J Biol Eng. 2014;8:14.

4. Ribeiro N, Sousa SR, van Blitterswijk CA, Moroni L, Monteiro FJ. A biocomposite of collagen nanofibers and nanohydroxyapatite for bone regeneration. Biofabrication. 2014;6(3):035015.
5. Bral A, Mommaerts MY. In vivo biofunctionalization of titanium patient-specific implants with nano hydroxyapatite and other nano calcium phosphate coatings: a systematic review. J Craniomaxillofac Surg. 2016;44(4):400-412.

6. Abd El-Fattah H, Helmy Y, El-Kholy B, Marie M. In vivo animal histomorphometric study for evaluating biocompatibility and osteointegration of nano-hydroxyapatite as biomaterials in tissue engineering. J Egypt Natl Canc Inst. 2014;22(4):241-250.

7. Zhou H, Lee J. Nanoscale hydroxyapatite particles for bone tissue engineering. Acta Biomater. 2011;7(7):2769-2781.

8. Shi Z, Huang X, Cai Y, Tang R, Yang D. Size effect of hydroxyapatite nanoparticles on proliferation and apoptosis of osteoblast-like cells. Acta Biomater. 2009;5(1):338-345.

9. Zhu W, Wang D, Peng L, et al. An experimental study on the application of radionuclide imaging in repairing bone defects. ArtifCells Nanomed Biotechnol. 2013;41(5):304-308.

10. Albini A, Mussi V, Parodi A, et al. Interactions of single-wall carbon nanotubes with endothelial cells. Nanomedicine. 2010;6(2):277-288.

11. Wang C, Lin K, Chang J, Sun J. Osteogenesis and angiogenesis induced by porous beta-CaSiO(3)/PDLGA composite scaffold via activation of AMPK/ERK1/2 and PI3K/Akt pathways. Biomaterials. 2013;34(1):64-77.

12. Bauer IW, Li SP, Han YC, Yuan L, Yin MZ. Internalization of hydroxyapatite nanoparticles in liver cancer cells. JMater Sci Mater Med. 2008; 19(3):1091-1095.

13. Santos C, Gomes PS, Duarte JA, et al. Relevance of the sterilizationinduced effects on the properties of different hydroxyapatite nanoparticles and assessment of the osteoblastic cell response. J R Soc Interface. 2012;9(77):3397-3410.

14. Pezzatini S, Solito R, Morbidelli L, et al. The effect of hydroxyapatite nanocrystals on microvascular endothelial cell viability and functions. J Biomed Mater Res A. 2006;76(3):656-663.

15. Holmes B, Bulusu K, Plesniak M, Zhang LG. A synergistic approach to the design, fabrication and evaluation of $3 \mathrm{D}$ printed micro and nano featured scaffolds for vascularized bone tissue repair. Nanotechnology. 2016;27(6):064001.

16. Lovren F, Pan Y, Shukla PC, et al. Visfatin activates eNOS via Akt and MAP kinases and improves endothelial cell function and angiogenesis in vitro and in vivo: translational implications for atherosclerosis. Am J Physiol Endocrinol Metab. 2009;296(6):E1440-E1449.

17. Chung BH, Kim JD, Kim CK, et al. Icariin stimulates angiogenesis by activating the MEK/ERK- and PI3K/Akt/eNOS-dependent signal pathways in human endothelial cells. Biochem Biophys Res Commun. 2008;376(2):404-408.

18. Cooney R, Hynes SO, Sharif F, Howard L, O'Brien T. Effect of gene delivery of NOS isoforms on intimal hyperplasia and endothelial regeneration after balloon injury. Gene Ther. 2007;14(5):396-404.

19. Tang JR, Seedorf G, Balasubramaniam V, Maxey A, Markham N, Abman SH. Early inhaled nitric oxide treatment decreases apoptosis of endothelial cells in neonatal rat lungs after vascular endothelial growth factor inhibition. Am J Physiol Lung Cell Mol Physiol. 2007;293(5): L1271-L1280.

20. Zheng ZZ, Liu ZX. Activation of the phosphatidylinositol 3-kinase/ protein kinase Akt pathway mediates CD151-induced endothelial cell proliferation and cell migration. Int J Biochem Cell Biol. 2007;39(2): 340-348.

21. Namkoong S, Chung BH, Ha KS, Lee H, Kwon YG, Kim YM. Microscopic technique for the detection of nitric oxide-dependent angiogenesis in an animal model. Methods Enzymol. 2008;441:393-402.

22. Liu X, Sun J. Endothelial cells dysfunction induced by silica nanoparticles through oxidative stress via JNK/P53 and NF-kappaB pathways. Biomaterials. 2010;31(32):8198-8209.

23. Lesniak A, Salvati A, Santos-Martinez MJ, Radomski MW, Dawson KA, Aberg C. Nanoparticle adhesion to the cell membrane and its effect on nanoparticle uptake efficiency. J Am Chem Soc. 2013;135(4):1438-1444.

24. Kuhn DA, Vanhecke D, Michen B, et al. Different endocytotic uptake mechanisms for nanoparticles in epithelial cells and macrophages. Beilstein J Nanotechnol. 2014;5:1625-1636. 
25. Li Z, Huve J, Krampe C, et al. Internalization pathways of anisotropic disc-shaped zeolite L nanocrystals with different surface properties in HeLa cancer cells. Small. 2013;9(9-10):1809-1820.

26. Kim YM, Namkoong S, Yun YG, et al. Water extract of Korean red ginseng stimulates angiogenesis by activating the PI3K/Akt-dependent ERK1/2 and eNOS pathways in human umbilical vein endothelial cells. Biol Pharm Bull. 2007;30(9):1674-1679.

27. Poh CK, Shi Z, Lim TY, Neoh KG, Wang W. The effect of VEGF functionalization of titanium on endothelial cells in vitro. Biomaterials. 2010;31(7):1578-1585.

28. Ha SW, Jang HL, Nam KT, Beck GR Jr. Nano-hydroxyapatite modulates osteoblast lineage commitment by stimulation of DNA methylation and regulation of gene expression. Biomaterials. 2015;65:32-42.

29. D'Elia NL, Mathieu C, Hoemann CD, Laiuppa JA, Santillan GE, Messina PV. Bone-repair properties of biodegradable hydroxyapatite nano-rod superstructures. Nanoscale. 2015;7(44):18751-18762.

30. Tang W, Yuan Y, Liu C, Wu Y, Lu X, Qian J. Differential cytotoxicity and particle action of hydroxyapatite nanoparticles in human cancer cells. Nanomedicine (Lond). 2013;9(3):397-412.

31. Tay CY, Fang W, Setyawati MI, et al. Nano-hydroxyapatite and nano-titanium dioxide exhibit different subcellular distribution and apoptotic profile in human oral epithelium. ACS Appl Mater Interfaces. 2014;6(9):6248-6256.

32. Remya NS, Syama S, Gayathri V, Varma HK, Mohanan PV. An in vitro study on the interaction of hydroxyapatite nanoparticles and bone marrow mesenchymal stem cells for assessing the toxicological behaviour. Colloids Surf B Biointerfaces. 2014;117:389-397.

33. Muzi L, Tardani F, La Mesa C, Bonincontro A, Bianco A, Risuleo G. Interactions and effects of BSA-functionalized single-walled carbon nanotubes on different cell lines. Nanotechnology. 2016;27(15): 155704.

34. Zhao X, Ng S, Heng BC, et al. Cytotoxicity of hydroxyapatite nanoparticles is shape and cell dependent. Arch Toxicol. 2013;87(6): 1037-1052.

35. Yuan Y, Liu C, Qian J, Wang J, Zhang Y. Size-mediated cytotoxicity and apoptosis of hydroxyapatite nanoparticles in human hepatoma HepG2 cells. Biomaterials. 2010;31(4):730-740.

36. Stefanutti E, Papacci F, Sennato S, et al. Cationic liposomes formulated with DMPC and a gemini surfactant traverse the cell membrane without causing a significant bio-damage. Biochim Biophys Acta. 2014; 1838(10):2646-2655.

37. Cosimati R, Milardi GL, Bombelli C, et al. Interactions of DMPC and DMPC/gemini liposomes with the cell membrane investigated by electrorotation. Biochim Biophys Acta. 2013;1828(2):352-356.

38. Dausend J, Musyanovych A, Dass M, et al. Uptake mechanism of oppositely charged fluorescent nanoparticles in HeLa cells. Macromol Biosci. 2008;8(12):1135-1143.

39. Chithrani BD, Ghazani AA, Chan WC. Determining the size and shape dependence of gold nanoparticle uptake into mammalian cells. Nano Lett. 2006;6(4):662-668.

40. Safi M, Courtois J, Seigneuret M, Conjeaud H, Berret JF. The effects of aggregation and protein corona on the cellular internalization of iron oxide nanoparticles. Biomaterials. 2011;32(35):9353-9363.
41. Doiron AL, Clark B, Rinker KD. Endothelial nanoparticle binding kinetics are matrix and size dependent. Biotechnol Bioeng. 2011;108(12): 2988-2998.

42. Motskin M, Wright DM, Muller K, et al. Hydroxyapatite nano and microparticles: correlation of particle properties with cytotoxicity and biostability. Biomaterials. 2009;30(19):3307-3317.

43. Nan A, Bai X, Son SJ, Lee SB, Ghandehari H. Cellular uptake and cytotoxicity of silica nanotubes. Nano Lett. 2008;8(8):2150-2154.

44. Gaiser BK, Fernandes TF, Jepson M, Lead JR, Tyler CR, Stone V. Assessing exposure, uptake and toxicity of silver and cerium dioxide nanoparticles from contaminated environments. Environ Health. 2009; 8( suppl 1):S2.

45. Kumari S, Mg S, Mayor S. Endocytosis unplugged: multiple ways to enter the cell. Cell Res. 2010;20(3):256-275.

46. Predescu SA, Predescu DN, Malik AB. Molecular determinants of endothelial transcytosis and their role in endothelial permeability. Am J Physiol Lung Cell Mol Physiol. 2007;293(4):L823-L842.

47. Wang Z, Tiruppathi C, Minshall RD, Malik AB. Size and dynamics of caveolae studied using nanoparticles in living endothelial cells. ACS Nano. 2009;3(12):4110-4116.

48. Komarova Y, Malik AB. Regulation of endothelial permeability via paracellular and transcellular transport pathways. Annu Rev Physiol. 2010;72:463-493.

49. Hubbell JA, Thomas SN, Swartz MA. Materials engineering for immunomodulation. Nature. 2009;462(7272):449-460.

50. Chen T, Chen N, Pang N, et al. Hydroxysafflor yellow a promotes angiogenesis via the angiopoietin 1/Tie-2 signaling pathway. J Vasc Res. 2016;53(5-6):245-254.

51. Wu QH, Ma Y, Ruan CC, et al. Loss of osteoglycin promotes angiogenesis in limb ischaemia mouse models via modulation of vascular endothelial growth factor and vascular endothelial growth factor receptor 2 signalling pathway. Cardiovasc Res. 2017;113(1):70-80.

52. Lu XL, Xu ZL, Yao XL, et al. Marine cyclotripeptide X-13 promotes angiogenesis in zebrafish and human endothelial cells via PI3K/Akt/ eNOS signaling pathways. Mar Drugs. 2012;10(6):1307-1320.

53. Yu S, Wong SL, Lau CW, Huang Y, Yu CM. Oxidized LDL at low concentration promotes in-vitro angiogenesis and activates nitric oxide synthase through PI3K/Akt/eNOS pathway in human coronary artery endothelial cells. Biochem Biophys Res Commun. 2011;407(1): 44- 48.

54. Xiao X, Wang W, Liu D, et al. The promotion of angiogenesis induced by three-dimensional porous beta-tricalcium phosphate scaffold with different interconnection sizes via activation of PI3K/Akt pathways. Sci Rep. 2015;5:9409.

55. Kang Z, Zhu H, Jiang W, Zhang S. Protocatechuic acid induces angiogenesis through PI3K-Akt-eNOS-VEGF signalling pathway. Basic Clin Pharmacol Toxicol. 2013;113(4):221-227.

56. Hung HS, Wu CC, Chien S, Hsu SH. The behavior of endothelial cells on polyurethane nanocomposites and the associated signaling pathways. Biomaterials. 2009;30(8):1502-1511. 


\section{Supplementary materials}
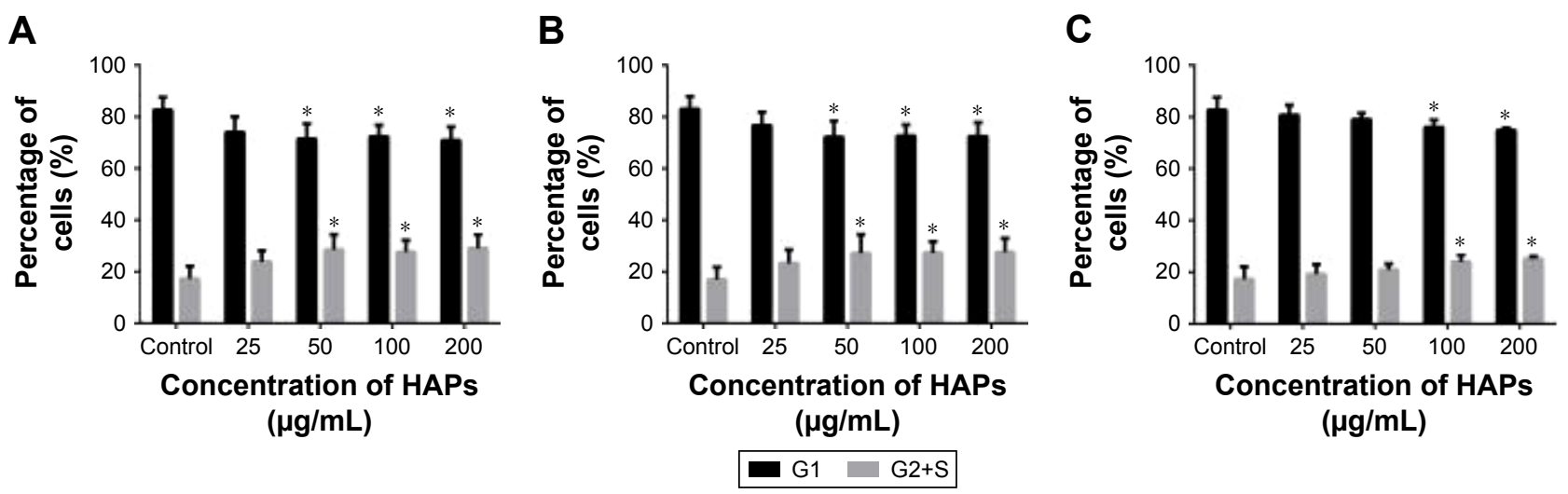

Figure SI Effects of HAPs on the cell cycle of HUVECs.

Notes: Cell cycle of HUVECs after treatment with np20 (A), np80 (B) and m-HAP (C) for 24 h. $* P<0.05$ versus control. Cells without HAP treatment were set as the control group.

Abbreviations: HAP, hydroxyapatite; HUVECs, human umbilical vein endothelial cells; m-HAP, micro-sized HAP particles.

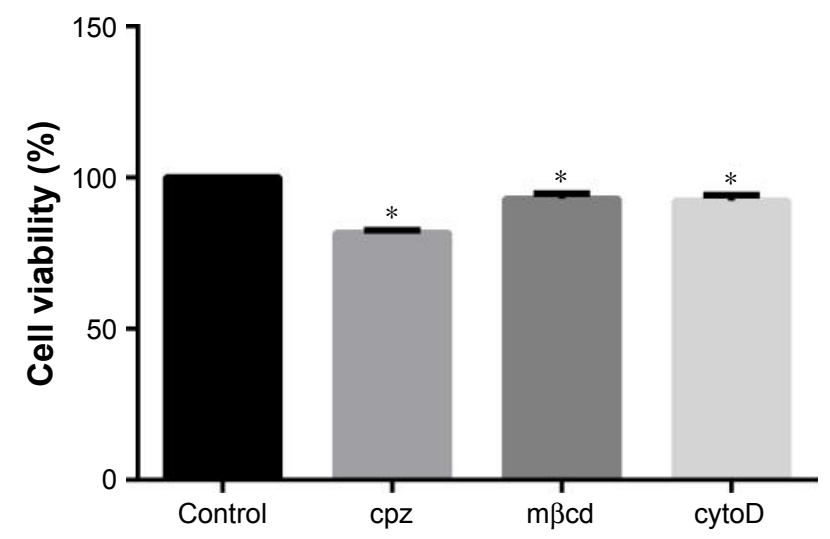

Figure S2 Effects of endocytosis inhibitors on cell viability.

Notes: The viability of HUVECs cultured with cpz, $\mathrm{m} \beta \mathrm{cd}$ and cytoD for $30 \mathrm{~min} . * \mathrm{P}<0.0 \mathrm{l}$ versus control. Cells without endocytosis inhibitors treatment were set as control group.

Abbreviations: cpz, chlorpromazine; cytoD, cytochalasin D; HUVECs, human umbilical vein endothelial cells; m $\beta$ cd, methyl- $\beta$-cyclodextrin.

\section{Publish your work in this journal}

The International Journal of Nanomedicine is an international, peerreviewed journal focusing on the application of nanotechnology in diagnostics, therapeutics, and drug delivery systems throughou the biomedical field. This journal is indexed on PubMed Central, MedLine, CAS, SciSearch $®$, Current Contents $\AA /$ Clinical Medicine,
Journal Citation Reports/Science Edition, EMBase, Scopus and the Elsevier Bibliographic databases. The manuscript management system is completely online and includes a very quick and fair peer-review system, which is all easy to use. Visit http://www.dovepress.com/ testimonials.php to read real quotes from published authors. 